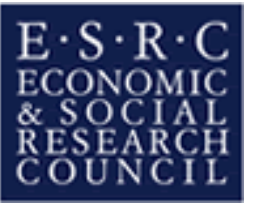

\title{
Market-Share Contracts with Asymmetric Information
}

\author{
by \\ Adrian Majumdar \\ Centre for Competition Policy, University of East Anglia \\ $\&$ \\ Greg Shaffer \\ Simon School of Business, University of Rochester \\ (etc)
}

\section{CCP Working Paper 07-17}

The support of the Economic and Social Research Council is also gratefully acknowledged. 


\title{
Market-Share Contracts with Asymmetric Information*
}

\author{
Adrian Majumdar $\quad$ Greg Shaffer ${ }^{\ddagger}$
}

July 2007

\begin{abstract}
In this paper, a dominant supplier and competitive fringe supply goods to a common buyer who has private information about the state of demand. We give conditions under which market-share contracts are profitable, and we show that, in some cases, the fullinformation outcome can be obtained (unlike in standard screening models, where the agent earns an information rent in the high state and demand is distorted in the low state). Our results also inform the antitrust debate on bundling, fidelity rebates and all-units discounts. We provide a new motive for a dominant firm to bundle its own product with a competitively supplied product (with ambiguous consequences for welfare), and we show that market-share contracts, which are a subset of fidelity rebates, are more profitable than all-units discounts.
\end{abstract}

JEL Classification: L13, L41, L42.

Keywords: Adverse Selection, Screening, Bundling, Fidelity Rebates, All-Units Discounts.

\footnotetext{
*We thank Stephen Davies for advice and encouragement and Alexia Gaudeul, Bruce Lyons, and other colleagues at the University of East Anglia for helpful comments. Remaining errors are our own.

${ }^{\dagger}$ Centre for Competition Policy, University of East Anglia. E-mail: adrian.majumdar@rbbecon.com

${ }^{\ddagger}$ Simon School of Business, University of Rochester. E-mail: shaffer@simon.rochester.edu.
} 


\section{Introduction}

In Europe and the US, there has been considerable debate over the competitive effects of marketshare discounts, fidelity rebates, all-units discounts (also known as rollback rebates) and bundled rebates when employed by dominant firms. The EC Commission has tended to presume that such forms of behavior, when employed by a dominant firm, are anti-competitive (see, for example, Whish 2003). In the US, the authorities and courts have been more circumspect. In part, this reflects a view that these practices are not well understood in the economics literature and so intervention would risk setting precedents that could chill pro-competitive behavior. ${ }^{1}$

This paper provides insights into all such forms of behavior when used by a dominant firm in a setting of asymmetric information. We start with a standard screening model in which the dominant firm seeks to induce its retailer to reveal the true state of demand and augment it by allowing the retailer to purchase, in addition to the dominant firm's product, a substitute good that is competitively supplied. ${ }^{2}$ Specifically, we assume that the dominant firm, M, is the sole supplier of good A, that good B is supplied by a competitive fringe, and that $\mathrm{R}$ is the retailer.

We show that when $\mathrm{M}$ is free to set a menu of contracts that specifies how much $\mathrm{R}$ must pay for any given quantity of good A that it purchases, the equilibrium contracts confirm the standard results in the incentives literature that in the low-demand state output is distorted downwards and $\mathrm{R}$ earns its outside option, while in the high-demand state $\mathrm{R}$ earns an information rent and there is no distortion in demand. However, when M can condition R's payment on not only how much of good A is purchased but also on how much of good B is purchased (market-share contracts), there are circumstances in which $\mathrm{M}$ achieves the full information outcome - in these cases there is no output distortion in the low-demand state and $\mathrm{R}$ earns no information rent.

This result is possible because unlike in standard screening models, the buyer's reservation utility from trading with the dominant supplier is not independent of the state of demand; in our model, the option of trading with the competitive fringe is worth more in the high-demand state

\footnotetext{
${ }^{1}$ This is reflected in the dispute in LePage's $v$. $3 M$ over bundled rebates, where the U.S. Solicitor General was invited by the Supreme Court to express the views of the federal government as to whether the case should be considered. The Solicitor General advised the Supreme Court not to consider the case due to a concern that an adverse precedent could be set because bundled rebates are a common practice and yet neither the economic theory on the matter nor the practical court cases were sufficiently developed to offer clear guidance (for a summary of the issues, see Office of Fair Trading, 2005, Annex C). On the more circumspect approach in the U.S. compared to Europe, see the discussion of Virgin Atlantic v. British Airways in Office of Fair Trading (2005), Annex B.

${ }^{2}$ Kolay et al (2004) consider a monopolist's use of all-units discounts in a related setting. However, they do not allow the retailer to purchase a substitute good nor do they consider market-share contracts or fidelity rebates.
} 
than in the low-demand state. ${ }^{3}$ We require only that relative to the low-demand state the highdemand state increases R's outside option (to purchase only good B) sufficiently. Intuitively, if R's outside option is more profitable than purchasing under M's contract in the low-demand state, then $\mathrm{M}$ no longer has an incentive to distort demand downwards in the low-demand state.

Even when the full-information outcome cannot be achieved, we find that market-share contracts are still always profitable for M when they are feasible. Specifying both a quantity and a market-share target in the same contract gives $\mathrm{M}$ more instruments with which to influence R's behavior. Absent market share contracts, M's attempts to induce R to reveal the true state of demand by restricting output of good $\mathrm{A}$ in the low state are hampered by the fact that $\mathrm{R}$ can substitute fewer units of good A for more units of good B. However, when M can contract on both $\mathrm{A}$ and $\mathrm{B}, \mathrm{M}$ restricts the amount of good $\mathrm{B}$ that $\mathrm{R}$ can purchase in the event that it conceals the true state and thereby $\mathrm{M}$ is able to slacken the incentive-compatibility constraint.

With respect to welfare, market-share contracts do not affect output in the high-demand state and so their impact is determined solely by their effect in the low-state. While the fullinformation outcome is typically good for welfare, in other circumstances welfare falls. For example, unless purchases of good A increase in the low state, welfare declines since purchases of good B decrease relative to the case without market-share contracts. We show that when demand is linear and symmetric, and the constant term varies with the state, welfare falls if demand is only 'a little' stronger in the high state but increases if demand is 'a lot' stronger. If demand is sufficiently strong in the high state, we find that the full-information outcome arises.

In short, the welfare effects of market-share contracts are ambiguous. This finding therefore does not support the presumption in European law that market-share targets are harmful (although neither is there support for the view that such targets are typically beneficial).

We consider various extensions to the model. First, we show that market-share contracts can be replicated by a combination of bundling and exclusive dealing. Thus, if market-share

\footnotetext{
${ }^{3}$ See Salanie (1997), Caillaud and Hermalin (2000), and Dewatripont and Bolton (2005) for reviews of the standard screening model, including extensions to a continuum of states (or types). However, unlike in this paper, each assumes that the agent's outside option is independent of its type. To our knowledge, Lewis and Sappington (1989) were the first to consider type dependence in a principal-agent model. They assume that the agent has private information about both its fixed and marginal costs, and show that this can lead to a situation in which the agent does not always have a systematic incentive to understate its private information. Jullien (2000) provides a general analysis of the adverse-selection problem when there is type dependence and also shows that the agent's information rent need not be increasing in its type. Here, we show that it will be increasing if the principal is restricted to contracting on its own quantity, but need not be if market-share contracts are feasible.
} 
contracts were prohibited, M could instead profitably monopolize the market for good B by producing its own B product and combining it in a pure bundle with its A product. Further, to control how much of good $\mathrm{B}$ that $\mathrm{R}$ buys in the high state, $\mathrm{M}$ would have to require that $\mathrm{R}$ deal exclusively with it (otherwise R could supplement its purchases of good B in the competitive market thereby undermining M's attempts to replicate a market-share target). Thus, we provide a new reason for a monopolist to bundle its product with a competitively supplied product. Further, a presumption that such bundling would increase welfare would not be appropriate. ${ }^{4}$

Second, we discuss the implications of our model for fidelity rebates, i.e., discounts that are based on the share of a buyer's needs sourced from the supplier in question. ${ }^{5}$ For example, market-share contracts can be thought as a special case of fidelity rebates because, with marketshare contracts, if the buyer fails to source at least the target share of its needs from M, it loses a very substantial discount (because then its per-unit price increases to infinity). The model also has implications for fidelity rebates even in the absence of market-share contracts provided it is reinterpreted as one with two buyers, one large and one small, but where $\mathrm{M}$ is prohibited from directly discriminating between buyers. For example, when M seeks to discriminate indirectly by inducing each buyer to reveal its true type, it may be that the profit-maximizing contracts give rise to discount structures that take the form of fidelity rebates. In this case, and in the cases where market-share contracts are feasible and observed, however, there is nothing peculiar about fidelity rebates per se. When they arise in equilibrium, fidelity rebates are used not with exclusionary intentions but simply as a device to induce buyers to reveal their true types.

Finally, we compare the profitability of market-share contracts, all-units discounts, and menus of two-part tariffs, and find that, unless market-share contracts are banned or infeasible, firms will prefer market-share contracts to all-units discounts and menus of two-part tariffs, as well as to all other discount schemes that are not conditional on purchases of rival products.

Relatively few other papers have considered market-share contracts in a formal game-theoretic

\footnotetext{
${ }^{4}$ In his review of the bundling literature, Nalebuff (2003) explains the Chicago-school view that when goods A and B are consumed in fixed proportions and B is supplied competitively, bundling occurs only for pro-competitive motives. However, in our paper, A and B need not be consumed in fixed proportions and so the Chicago-school presumption does not apply. See also the important contributions by Nalebuff (2005) and Greenlee et al (2004).

${ }^{5}$ This definition stems from the decision in Hoffmann-La Roche $v$ Commission, where the European Court of Justice stated that it is unlawful for a dominant firm to use "fidelity rebates," where the latter are defined as "discounts conditional on the customer's obtaining all or most of its requirements - whether the quantity of its purchases be large or small-from the undertaking in a dominant position" (as quoted in Whish 2003; p. 695).
} 
setting, ${ }^{6}$ and all of these consider a context that is different from the one proposed in our paper. Marx and Shaffer (2004) consider how market-share contracts may constitute an effective tool for rent shifting when firms contract sequentially. Further, Marx and Shaffer show how a ban on such contracts can be harmful, leading to exclusion that otherwise would not occur.

Mills (2004) considers how market-share targets may induce retailers to merchandise the product of a vertically-differentiated supplier when some consumers are uninformed and cannot tell the difference between the high-quality good and a competitively-supplied inferior substitute. Mills shows how conditioning rebates on the share of retailers' sales that are accounted for by a dominant firm may induce retailers to inform customers when monitoring merchandising effort would otherwise be too costly. A ban on market-share targets in his model would be harmful.

Greenlee and Reitman (2004) consider market-share targets ('loyalty programs') that allow buyers to qualify for discounts on all units purchased when a market-share target is met (the discount is relative to the spot price paid by those outside of the program). They compare competition in spot prices only with competition in spot prices and loyalty programs (i.e. other types of non-linear pricing, such as two-part tariffs, are implicitly assumed not to be feasible). Consumers are heterogenous in that it is not feasible to offer a loyalty program to small customers. All customers make more than one purchase and large customers are able to allocate their total purchases so as to ensure that they meet any accepted market-share target with certainty. ${ }^{7}$ They find that typically the spot-price only equilibrium will not arise because it will be profitable for firms to target some customers with loyalty programs. Further, they show that only one firm's loyalty program will be accepted in any equilibrium with loyalty discounts.

In a related paper, Marvel and Yang (2006) assume a Hotelling setting and show that the creation of a buyer group allows suppliers to use non-linear tariffs. As a result, suppliers compete not only for the marginal consumer but also for inframarginal consumers and so competition is intensified. A ban on non-linear tariffs in their model would lead to higher prices for consumers.

Unlike these papers, Ordover and Shaffer (2006) consider the exclusionary effects of marketshare targets. They analyze a two-period model with two sellers and one buyer where the efficient outcome would have the buyer purchase one unit from each seller in each period. Switching costs

\footnotetext{
${ }^{6}$ For a discussion of the competitive effects of loyalty rebates and other forms of discounts in an informal setting, see Office of Fair Trading (2005) and the papers by Spector, Kobayashi, and Heimler in "A Symposium on Loyalty Rebates" (2005).

${ }^{7}$ One interpretation is that large customers can be thought of as a buyer group who are acting on behalf of consumers located along a Hotelling line. The larger the market-share target, the more the buyer group would have to shift some consumers away from their preferred supplier (and hence the larger the discount required).
} 
mean that purchasing a unit from a seller in the period 1 locks-in the buyer to purchasing a unit from the same seller in period 2. As a result, competition between sellers calls for belowcost prices in period 1 to compensate for the monopoly price that will be charged on captive units in period 2. ${ }^{8}$ Assuming the dominant firm already has a captive unit in the first period, the implied price for the second unit must be below cost and so the dominant firm can be thought of as offering a fidelity rebate or a market-share discount. Ordover and Shaffer show that, where the rival is financially constrained, the dominant firm may profitably exclude an equally efficient rival, since the rival cannot refund sufficient amounts to the buyer to secure a first-period sale. Further, they show that both efficient and exclusionary equilibria occur with implied prices below cost for the second unit. They then demonstrate that a ban on discounts that have implied prices below cost would eliminate exclusionary outcomes without reducing the scope for efficient outcomes, while a ban on implied negative prices (an easier policy to apply) would reduce harmful outcomes without impacting the scope for efficient outcomes.

It is helpful to clarify terminology in this literature. Marx and Shaffer (2004) define marketshare contracts as those that allow M to condition R's payment on the specific quantities of M's good and a second product that R may purchase. This is not the same as a target that links payment only to the share of R's purchases accounted for by M's product unless the target is combined with a quantity target for M's product as well (as in section 3 of this paper) or the market size is fixed (as is the case in (most of) Mills (2004) and the other models above). ${ }^{9}$

The rest of the paper is set out as follows. Section 2 describes the model and characterizes the equilibrium with quantity targets. Section 3 introduces market-share contracts. Section 4 solves a linear demand example and offers welfare conclusions. Section 5 discusses the implications of the model for bundling, fidelity rebates and all-units discounts. Section 6 contains the conclusion.

\section{The Basic Model: equilibrium with quantity targets}

In this section we describe the basic model. There are two goods, A and B, which are imperfect substitutes. Good $\mathrm{A}$ is produced at marginal $\operatorname{cost} c_{A}$ by a 'monopolist', which we denote M.

\footnotetext{
${ }^{8}$ Long-term contracts which specify prices in period two are assumed to be infeasible in their model.

${ }^{9}$ For example, suppose that a 'market-share contract' allows $\mathrm{R}$ to earn a discount if it buys exactly 70 units of product A and exactly 30 units of product B. A share of buyer's purchases target set at $70 \%$ would allow $\mathrm{R}$ to earn a discount not only when it buys 70 units of A and 30 units of B but also 35 units of A and 15 units of B, 140 units of $\mathrm{A}$ and 60 units of $\mathrm{B}$, and so on. However, if the market-share target of $70 \%$ is combined with a quantity target of 70 units of good A, or if the market size is fixed at 100 units, then the two contracts are equivalent.
} 
Good B is produced at marginal cost $c_{B}$ and sold competitively by numerous identical suppliers. There is one buyer, $\mathrm{R}$. $\mathrm{R}$ is a retailer that buys goods $\mathrm{A}$ and $\mathrm{B}$ and resells them to final consumers.

There are two stages to the game. ${ }^{10}$ At stage $1, \mathrm{M}$ offers $\mathrm{R}$ a menu of contracts which specify quantity targets. We denote a contract by $\{T(A), A\}$, i.e. in order to purchase $A$ units of good $\mathrm{A}, \mathrm{R}$ must pay $\mathrm{M}$ a fee of $T(A)$. Although $\mathrm{M}$ knows what demand for goods $\mathrm{A}$ and $\mathrm{B}$ would be in each state, as well as the probability of each state occurring, M does not know which state will occur when it sets its menu of contracts. At stage 2, $\mathrm{R}$ observes the state of demand, purchases the most profitable combination of goods A and B, and resells those goods to final consumers.

In the absence of a competitive fringe selling good B, this situation would be 'standard' in the incentives literature. $\mathrm{R}$ would earn its outside option in the low state and an information rent in the high state. Further, output would be distorted downwards in the low state, while in the high state there would be no distortion (i.e. output would maximize the available surplus). Our first task here is to assess how these results might change if $\mathrm{R}$ were allowed in addition to purchase a second good, good B, that is supplied by a competitive market. As we will show, the answer depends on whether $\mathrm{M}$ can offer a menu of quantity targets only (as in this section), or whether in addition to quantity targets it can offer a menu of market-share targets (as in the next section). ${ }^{11}$

Stage 2: Reselling. Denote R's revenue function in state $S$ by $R^{S}(A, B)$, where $A$ denotes the quantity sold of good A, $B$ denotes the quantity sold of good B, and $S$ stands for the state of demand ( $S \in\{L, H\}$, where $L$ is 'low' and $H$ is 'high'). Further, let

$$
\beta^{S}(A) \equiv \arg \max _{B} R^{S}(A, B)-c_{B} B
$$

denote the quantity of good B that $\mathrm{R}$ would purchase (and resell) in state $S$ as a function of how much it purchases (and resells) of good A. This allows us to define the overall 'gross-surplus function' (i.e., R's profit gross of any fee it pays to M) in terms of good A only as follows:

$$
g^{S}(A) \equiv R^{S}\left(A, \beta^{S}(A)\right)-c_{A} A-c_{B} \beta^{S}(A) .
$$

For simplicity, we assume $c_{A}=c_{B}=0$. We also make the following standard assumptions:

Assumption 1 R's overall gross-surplus function is twice differentiable, strictly concave, and has an interior maximum, which solves $\frac{\partial g^{S}(A)}{\partial A}=0$.

\footnotetext{
${ }^{10}$ The stages are similar to those in Kolay et al (2004), although they do not allow R to purchase good B.

${ }^{11}$ For ease of exposition we treat the market for good B as being perfectly competitive. In principle, however, one could think of good $\mathrm{B}$ as being supplied by a rival firm that has market power with no change in the qualitative results, if the price of good $B$ that is set by the rival is unaffected by the menu of contracts offered by $M$ to $R$.
} 


\section{Figure 1: Gross surplus function}

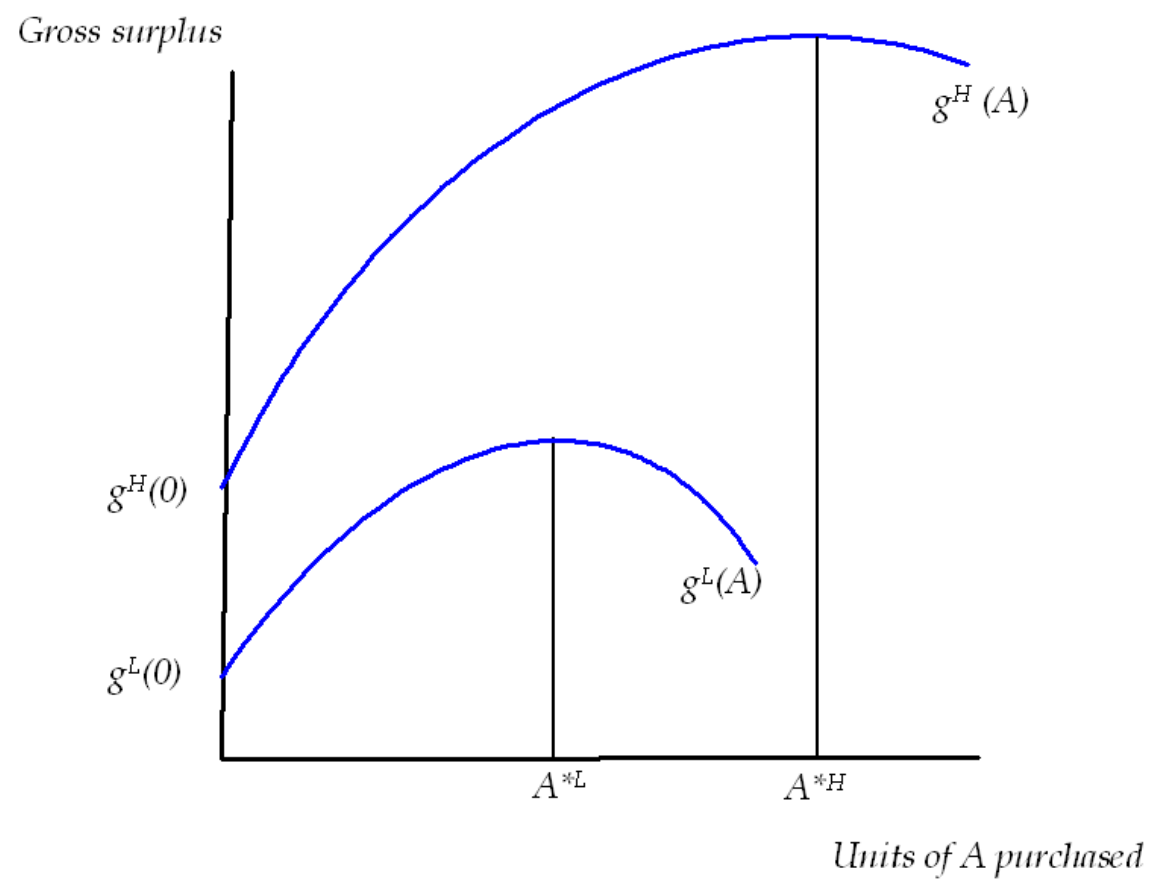

Assumption 2 The value of $R$ 's outside option in state $S$ is such that $g^{H}(0) \geq g^{L}(0)$.

Unlike much of the incentives literature, we do not restrict the value of R's outside option to be zero or some positive constant, but instead allow it to vary with the state of demand. Indeed, as we shall see, obtaining the full-information outcome requires that $g^{H}(0)>g^{L}(0)$.

Assumption 3 For all $A \geq 0$, the value of an additional unit of $A$ is such that $\frac{\partial g^{H}(A)}{\partial A}>\frac{\partial g^{L}(A)}{\partial A}$.

This assumption is known as the 'single-crossing property' in the incentives literature, and it allows $\mathrm{M}$ to induce truth telling by distorting output in the low state. The more output is reduced in the low state, the more $\mathrm{R}$ is penalized for concealing the high state- because the decrease in sales implies greater forgone profit for $\mathrm{R}$ in the high state compared to the low state.

In what follows, it is useful to note that Assumptions 2 and 3 imply that $g^{H}(A)>g^{L}(A)$ for all $A>0$, and that $g^{H}(A)-g^{L}(A)$ is increasing in $A$ for all $A \geq 0$. Moreover, as illustrated in Figure 1 above, Assumptions 1 and 3 imply that $A^{* H}>A^{* L}$, where $A^{* S} \equiv \arg \max g^{S}(A)$. 
Stage 1: Contracts offered to R. We now consider how, at stage 1 (prior to the revelation of demand), M can induce truth telling by the appropriate choice of quantity targets and fees. Denote a contract that induces truth telling in state $S$ as $\left\{T^{S}, A^{S}\right\}$, where $T^{S}$ is the tariff paid to $\mathrm{M}$ when $A^{S}$ units of good $\mathrm{A}$ are purchased. Then, individual rationality requires that $\mathrm{R}$ earns its 'outside option' (what it could earn by purchasing only from B) in the low-demand state:

$$
g^{L}\left(A^{L}\right)-T^{L}=g^{L}(0)
$$

and incentive compatibility requires that $\mathrm{R}$ must not want to conceal the high demand state:

$$
g^{H}\left(A^{H}\right)-T^{H}=g^{H}\left(A^{L}\right)-T^{L} .
$$

We now turn to M's maximization problem. ${ }^{12}$ This is to choose $A^{L}$ and $A^{H}$ to maximize:

$$
p T^{L}+(1-p) T^{H}
$$

where $T^{L}$ and $T^{H}$ are implicitly given by equations (3) and (4) and where $p$ refers to the probability of the low-demand state occurring. The resulting maximand is:

$$
g^{L}\left(A^{L}\right)-g^{L}(0)+(1-p)\left(g^{H}\left(A^{H}\right)-g^{H}\left(A^{L}\right)\right),
$$

and the first-order conditions are:

$$
(1-p) \frac{\partial g^{H}\left(A^{H}\right)}{\partial A}=0
$$

and

$$
\frac{\partial g^{L}\left(A^{L}\right)}{\partial A}-(1-p) \frac{\partial g^{H}\left(A^{L}\right)}{\partial A}=0 .
$$

Equation (7) indicates that $\mathrm{M}$ chooses $A^{H}$ to be the full-information quantity, $A^{\star H}$ (recall that $A^{\star H}$ solves $\left.\frac{\partial g^{H}\left(A^{H}\right)}{\partial A}=0\right)$. Intuitively, $\left\{T^{L}, A^{L}\right\}$ pins down R's profit from failing to tell the truth in the high-demand state. Since the latter is unaffected by $A^{H}$, M simply maximizes the surplus in the high-demand state so as to extract as high a payment $T^{H}$ from $\mathrm{R}$ as possible.

Equation (8) indicates that $\mathrm{M}$ chooses $A^{L}$ to be less than $A^{\star L}$ (recall that $A^{\star L}$ solves $\left.\frac{\partial g^{L}\left(A^{L}\right)}{\partial A}=0\right)$. This is because $-(1-p) \frac{\partial g^{H}\left(A^{L}\right)}{\partial A}$ is negative, since $\frac{\partial g^{H}\left(A^{L}\right)}{\partial A}>0$ for $A^{L}=A^{\star L}<$ $A^{\star H}$. The intuition is as follows. The first term is the lost profit arising from having to lower $T^{L}$ to ensure that the participation constraint is met. ${ }^{13}$ This is equated to the higher expected profit gained from relaxing the incentive-compatibility condition, which allows for a higher $T^{H}$.

\footnotetext{
${ }^{12}$ It is straightforward to verify that our assumptions ensure that $\mathrm{R}$ purchases from $\mathrm{M}$ in the high demand state and that, in the low demand state, $\mathrm{R}$ would not purchase the contract designed by $\mathrm{M}$ for the high demand state.

${ }^{13}$ This profit is lost with certainty because, ceteris paribus, the lower $T^{L}$ not only reduces R's low-demand payment but also R's high-demand payment (by improving R's profit from concealing the high-demand state).
} 
Figure 2: Quantity targets - Equilibrium output and tariffs

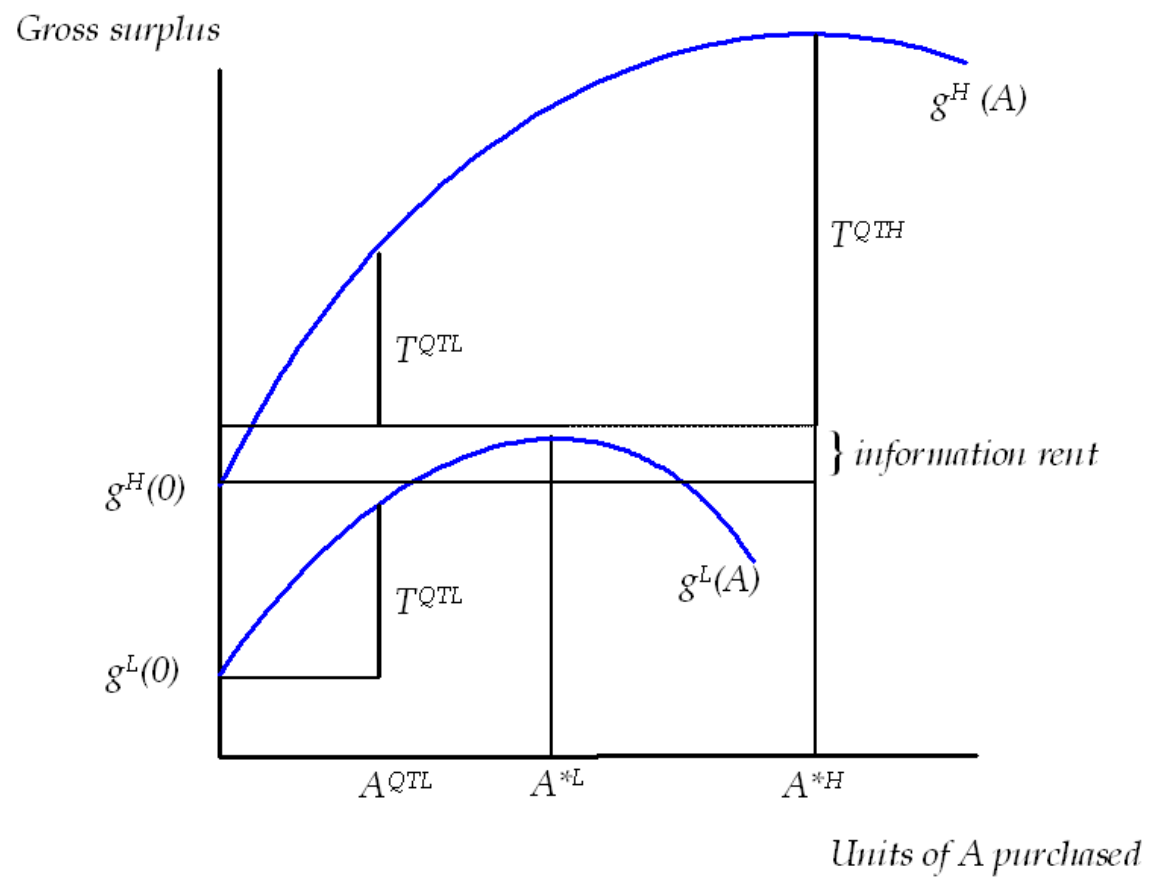

Let $\left\{T^{Q T H}, A^{Q T H}\right\}$ and $\left\{T^{Q T L}, A^{Q T L}\right\}$ denote M's profit-maximizing menu of contract offers, where $A^{Q T H}$ and $A^{Q T L}$ denote M's quantity targets in the high and low states, respectively, and $T^{Q T H}$ and $T^{Q T L}$ are the associated tariffs. Then, (7) and (8) confirm the standard result in the incentives literature that $\mathrm{M}$ chooses a lower quantity in the low-demand state (compared to the 'full information regime' where M knows the state before it chooses contracts), $A^{Q T L}<A^{\star L}$, but does not distort quantity in the high-demand state, $A^{Q T H}=A^{\star H}$. Figure 2 is illustrative.

M's profit in this case is therefore

$$
p T^{Q T L}+(1-p) T^{Q T H}
$$

where $T^{Q T L}$ and $T^{Q T H}$ are given by

$$
T^{Q T L}=g^{L}\left(A^{Q T L}\right)-g^{L}(0)
$$

and

$$
T^{Q T H}=g^{H}\left(A^{Q T H}\right)-\left(g^{H}\left(A^{Q T L}\right)-T^{Q T L}\right) .
$$


Note that if goods $A$ and $B$ are strategic substitutes (see Bulow et al, 1985), then $\beta^{S}(A)$ is decreasing in $A$, which implies that $\beta^{L}\left(A^{Q T L}\right)>\beta^{L}\left(A^{\star L}\right)$. This means that the downward distortion in good $A$ may be accompanied by an upward distortion in good $B$ relative to the full-information outcome. This has welfare implications, as we discuss in the next section.

Note also that $\mathrm{R}$ earns informational rent in the high-demand state. This is because R's payoff in the high-demand state, $g^{H}\left(A^{Q T L}\right)-T^{Q T L}$, is strictly greater than its outside option in this state, $g^{H}(0)$, given that the difference $g^{H}(A)-g^{L}(A)$ is increasing in $A$. Surprisingly, this finding does not necessarily hold in the next section, where we introduce market-share contracts.

\section{Market-share contracts}

We now consider how the introduction of market-share contracts can improve M's profit. Under a market-share contract, $\mathrm{M}$ sets both a quantity target and a market-share target (MST), where the latter specifies the share of R's total purchase that must be sourced from M in state $S .{ }^{14}$

Denote M's market-share contract for state $S$ by $\left\{T^{S}, A^{S}, X^{S}\right\}$, where $A^{S}$ is the quantity of good A that R must purchase and $X^{S} \equiv \frac{A^{S}}{A^{S}+B^{S}}$ is the MST. Note that with $A^{S}$ fixed, this effectively forces $\mathrm{R}$ to purchase $B^{S}$ units of good B. Thus, one can either think of $T^{S}$ as the tariff paid to $\mathrm{M}$ when $A^{S}$ units of good $\mathrm{A}$ are purchased and share $X^{S}$ is sourced from $\mathrm{M}$, or, equivalently, as the tariff paid to $\mathrm{M}$ when $\mathrm{R}$ buys $A^{S}$ units of good $\mathrm{A}$ and $B^{S}$ units of good $\mathrm{B}$.

Denote the MST that corresponds to the share of R's total purchase that would be sourced from M in state $S$ under truth telling when only quantity targets are feasible by

$$
X^{Q T S} \equiv \frac{A^{Q T S}}{A^{Q T S}+\beta^{S}\left(A^{Q T S}\right)} .
$$

Then, as we now show, if $\beta^{H}\left(A^{Q T L}\right) \neq \beta^{L}\left(A^{Q T L}\right)$, M can earn strictly higher profit when market-share targets are also feasible by offering $\mathrm{R}$ the menu of contracts

$$
\left\{\tilde{T}^{Q T H}, A^{Q T H}, X^{Q T H}\right\} \text { and }\left\{T^{Q T L}, A^{Q T L}, X^{Q T L}\right\}
$$

where

$$
\tilde{T}^{Q T H}=g^{H}\left(A^{Q T H}\right)-\max \left\{g^{H}(0), R^{H}\left(A^{Q T L}, \beta^{L}\left(A^{Q T L}\right)\right)-T^{Q T L}\right\} .
$$

This follows from two observations. First, note that the contracts in (12) satisfy all individualrationality and incentive-compatibility constraints (this follows by noting that the market-share

\footnotetext{
${ }^{14}$ We assume that the share of R's total purchases sourced from $\mathrm{M}$ can be verified at the time $\mathrm{R}$ makes a payment to $\mathrm{M}$. This is a reasonable assumption — otherwise firms would not be able to enforce the MSTs that are observed in practice.
} 
targets are such that R's gross surplus under truth telling is $g^{L}\left(A^{Q T L}\right)$ if the low state occurs and $g^{H}\left(A^{Q T H}\right)$ if the high state occurs). Second, note that if $\beta^{H}\left(A^{Q T L}\right) \neq \beta^{L}\left(A^{Q T L}\right)$ then M's tariff in the high-demand state is strictly higher, $\tilde{T}^{Q T H}>T^{Q T H}$, while M's tariff in the low-demand state is unchanged relative to the tariffs when only quantity targets are feasible.

To understand this last inequality, note that $\mathrm{R}$ earning positive rent in the high state with quantity targets implies $g^{H}\left(A^{Q T L}\right)-T^{Q T L}>g^{H}(0)$, and if $\beta^{H}\left(A^{Q T L}\right) \neq \beta^{L}\left(A^{Q T L}\right)$ then

$$
\begin{aligned}
g^{H}\left(A^{Q T L}\right)-T^{Q T L} & =R^{H}\left(A^{Q T L}, \beta^{H}\left(A^{Q T L}\right)\right)-T^{Q T L} \\
& >R^{H}\left(A^{Q T L}, \beta^{L}\left(A^{Q T L}\right)\right)-T^{Q T L},
\end{aligned}
$$

where the inequality in (14) follows from the definition of $\beta^{S}(A)$ (if the high state has occurred then R's 'unconstrained' optimal choice of good $\mathrm{B}$ is $\beta^{H}(A)$ not $\left.\beta^{L}(A)\right)$. This implies that

$$
\begin{aligned}
\tilde{T}^{Q T H}-T^{Q T H} & =g^{H}\left(A^{Q T L}\right)-T^{Q T L}-\max \left\{g^{H}(0), R^{H}\left(A^{Q T L}, \beta^{L}\left(A^{Q T L}\right)\right)-T^{Q T L}\right\} \\
& >0 .
\end{aligned}
$$

Since M's tariff in the low state is unchanged, it follows from (15) that if $\beta^{H}\left(A^{Q T L}\right) \neq$ $\beta^{L}\left(A^{Q T L}\right)$ then the menu of contract offers in (12) yields strictly higher profit for $\mathrm{M}$ than $\mathrm{M}$ would earn under its profit-maximizing menu of contract offers with quantity targets only.

We have thus shown the following result:

Proposition 1 If $\beta^{H}\left(A^{Q T L}\right) \neq \beta^{L}\left(A^{Q T L}\right)$, then market-share contracts can be used to increase $M$ 's profit vis a vis its maximized profit when only quantity targets are feasible.

The addition of the MST provides M with another means to extract surplus. If R's demand for good $\mathrm{B}$ when it purchases $A^{Q T L}$ units of good A differs across states, then $\mathrm{M}$ can use the target to lower R's profit from concealing the high-demand state by constraining $\mathrm{R}$ to purchase $\beta^{L}\left(A^{Q T L}\right)$ units of good $\mathrm{B}$ when ideally $\mathrm{R}$ would like to purchase an amount equal to $\beta^{H}\left(A^{Q T L}\right)$.

\subsection{Discussion}

An MST combined with a quantity target for good A pins down exactly the quantity of good B that $\mathrm{R}$ must purchase. As we shall see, this is often a needlessly strong restriction. If, as seems plausible in many cases, $\mathrm{R}$ would optimally purchase more of good $\mathrm{B}$ in the high-demand state than in the low-demand state for any given quantity of good A purchased, then the introduction of contracts that specify minimum market share targets for good A can also be profitable for M. 
Proposition 2 If $\beta^{H}\left(A^{Q T L}\right)>\beta^{L}\left(A^{Q T L}\right)$, then $M$ can increase its profit (relative to the quantity targets only regime) by offering a contract that specifies a minimum market-share target.

Proof: Let $\left\{T^{S}, A^{S}, \geq X^{S}\right\}$ denote a market-share contract in which M requires $\mathrm{R}$ to purchase $A^{S}$ units of good A and give it a minimum market share of $X^{S}$. Note that under this contract, even with $A^{S}$ fixed, the exact quantity of good B is not pinned down. Instead, M only effectively forces $\mathrm{R}$ to purchase at most $B^{S}$ units of good $\mathrm{B}$. Thus, for example, if the high-demand state occurs but $\mathrm{R}$ chooses to operate under contract $\left\{T^{Q T L}, A^{Q T L}, \geq X^{Q T L}\right\}$, then its payoff is

$$
\max _{B \leq \beta^{L}\left(A^{Q T L}\right)} R^{H}\left(A^{Q T L}, B\right)-T^{Q T L},
$$

which is weakly higher than its payoff would be if it had no flexibility in choosing the quantity of good B. Thus, the menu of contract offers in (12) may no longer be incentive-compatible if the MST target in the low-demand state is modified to allow for a minimum market share.

Consider, however, the menu of contracts

$$
\left\{\tilde{\tilde{T}}^{Q T H}, A^{Q T H}, \geq X^{Q T H}\right\} \quad \text { and } \quad\left\{T^{Q T L}, A^{Q T L}, \geq X^{Q T L}\right\}
$$

where

$$
\tilde{\tilde{T}}^{Q T H}=g^{H}\left(A^{Q T H}\right)-\max \left\{g^{H}(0), \max _{B \leq \beta^{L}\left(A^{Q T L}\right)} R^{H}\left(A^{Q T L}, B\right)-T^{Q T L}\right\} .
$$

Then, it is straightforward to show that all individual-rationality and incentive-compatibility constraints are satisfied (note that the minimum MSTs do not constrain R's profit-maximizing choice of good B under truth telling), and thus, since the tariff in the low-demand state is unchanged, $\mathrm{M}$ earns higher profit with these contracts (than it does with quantity targets only) if and only if its tariff in the high-demand state is strictly higher, i.e., if and only if $\tilde{\tilde{T}}^{Q T H}>T^{Q T H}$.

Subtracting $T^{Q T H}$ from $\tilde{\tilde{T}}^{Q T H}$, and noting that our Assumption 3 implies that $g^{H}\left(A^{Q T L}\right)-$ $T^{Q T L}>g^{H}(0)$, it follows that $\tilde{\tilde{T}}^{Q T H}-T^{Q T H}>0$ holds if

$$
R^{H}\left(A^{Q T L}, \beta^{H}\left(A^{Q T L}\right)\right)-T^{Q T L}>\max _{B \leq \beta^{L}\left(A^{Q T L}\right)} R^{H}\left(A^{Q T L}, B\right)-T^{Q T L},
$$

which holds if $\beta^{H}\left(A^{Q T L}\right)>\beta^{L}\left(A^{Q T L}\right)$ because then $\beta^{H}\left(A^{Q T L}\right)$ is not in R's feasible set $\left(A^{Q T L}\right.$ and $\beta^{H}\left(A^{Q T L}\right)$ would not satisfy M's minimum market-share requirement of $\left.X^{Q T L}\right)$. Q.E.D.

Once again the intuition is that $\mathrm{M}$ effectively reduces R's profit from concealing the highdemand state by forcing it to purchase less of good B than it would like when it misreports, while otherwise leaving R's incentives under truth telling unchanged. This reduces R's informational rent and allows $\mathrm{M}$ to extract a higher profit by setting a higher tariff in the high-demand state. 


\subsection{Characterizing the optimal market-share contract}

Consider again the contract $\left\{T^{S}, A^{S}, X^{S}\right\}$, where $T^{S}$ is the fee paid to $\mathrm{M}$ when $A^{S}$ units of $\mathrm{A}$ are purchased and $X^{S}$ is the share accounted for by good A as a percentage of R's total purchase volume. Then, as we have seen, this effectively pins down the quantity of good B that $\mathrm{R}$ must purchase. Thus, in the MST regime, one can think of $\mathrm{M}$ as choosing $A^{S}$ and $B^{S}$ to maximize:

$$
p T^{L}+(1-p) T^{H}
$$

subject to the following two constraints. First, individual rationality requires that $T^{L}$ is chosen such that R earns its outside option (purchasing only good B) in the low-demand state:

$$
R^{L}\left(A^{L}, B^{L}\right)-T^{L}=g^{L}(0) .
$$

Second, individual rationality and incentive compatibility requires that $T^{H}$ is chosen such that:

$$
R^{H}\left(A^{H}, B^{H}\right)-T^{H}=\max \left\{R^{H}\left(A^{L}, B^{L}\right)-T^{L}, g^{H}(0)\right\} .
$$

Thus, if the high-demand state occurs, $\mathrm{R}$ must not strictly prefer to misreport that the low-demand state has occurred, and R must not strictly prefer to purchase only good B.

Substituting the $T^{L}$ and $T^{H}$ that satisfy (21) and (22) into (20) yields

$$
\begin{gathered}
p\left(R^{L}\left(A^{L}, B^{L}\right)-g^{L}(0)\right)+ \\
(1-p)\left(R^{H}\left(A^{H}, B^{H}\right)-\max \left\{R^{H}\left(A^{L}, B^{L}\right)-R^{L}\left(A^{L}, B^{L}\right)+g^{L}(0), g^{H}(0)\right\}\right),
\end{gathered}
$$

from which it follows that there are two cases of interest: the case where

$$
R^{H}\left(A^{L}, B^{L}\right)-R^{L}\left(A^{L}, B^{L}\right)+g^{L}(0) \geq g^{H}(0)
$$

and the case where

$$
R^{H}\left(A^{L}, B^{L}\right)-R^{L}\left(A^{L}, B^{L}\right)+g^{L}(0) \leq g^{H}(0) .
$$

In both cases, it is straightforward to verify that in the high-demand state quantities $A^{H}$ and $B^{H}$ are chosen to maximize gross surplus and so the MST in the high-demand state is of no consequence for M. Our focus is therefore on the choice of $A^{L}$ and $B^{L}$ in the low-demand state.

Case 1: We say that Case 1 applies in the low-demand state if $A^{L}$ and $B^{L}$ are such that

$$
R^{H}\left(A^{L}, B^{L}\right)-R^{L}\left(A^{L}, B^{L}\right)+g^{L}(0) \geq g^{H}(0)
$$


Figure 3: Market share targets - Case 1

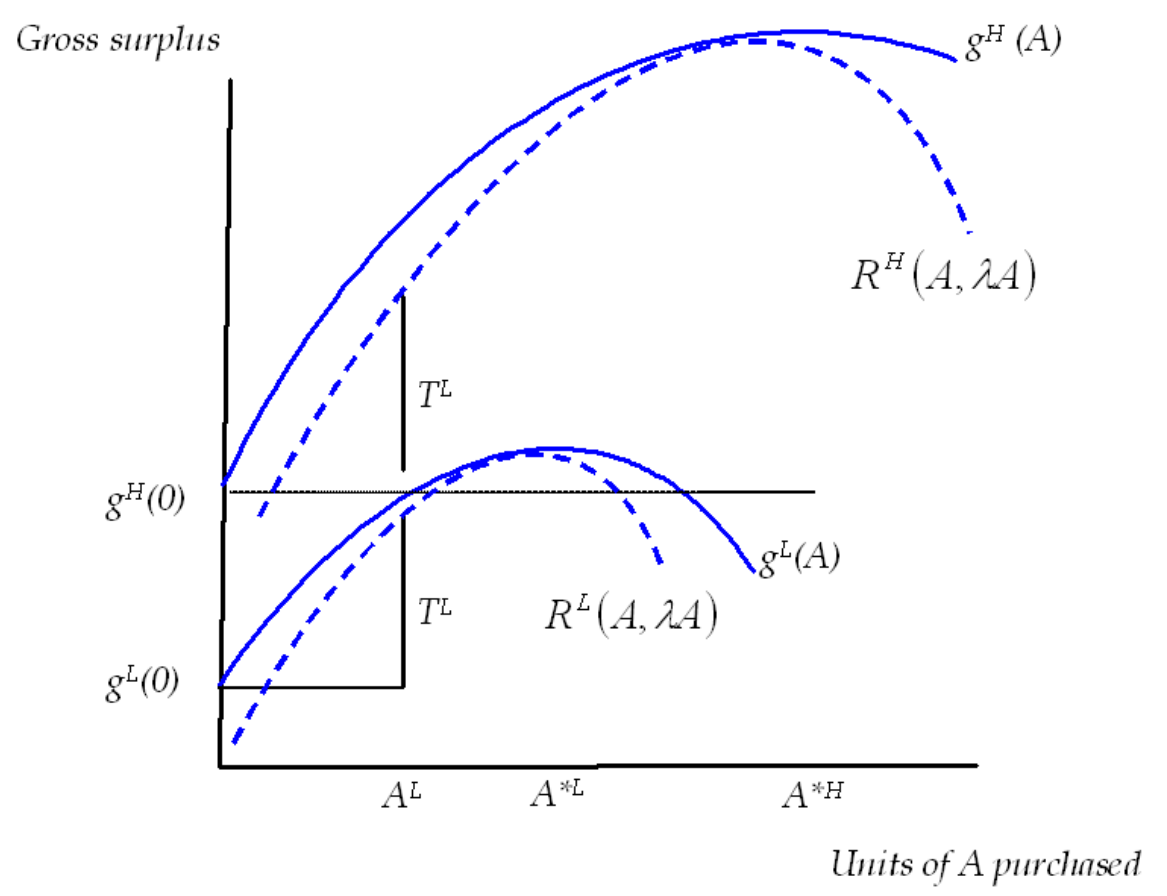

holds and $A^{L}$ and $B^{L}$ satisfy the first-order conditions:

$$
\frac{\partial R^{L}\left(A^{L}, B^{L}\right)}{\partial A}-(1-p) \frac{\partial R^{H}\left(A^{L}, B^{L}\right)}{\partial A}=0
$$

and

$$
\frac{\partial R^{L}\left(A^{L}, B^{L}\right)}{\partial B}-(1-p) \frac{\partial R^{H}\left(A^{L}, B^{L}\right)}{\partial B}=0 .
$$

Note that equation (24) is similar to equation (8) in the quantity targets only regime in that it implies that for a given quantity of good $\mathrm{B}, A^{L}$ does not maximize $R^{L}\left(A^{L}, B\right)$. However, unlike in the regime with quantity targets only, where $\mathrm{R}$ is free to purchase units of good $\mathrm{B}$ optimally, the MST regime induces R to purchase a lower amount of good B than ideally it would like (for a given $A^{L}$ ). It follows that R's gross revenue in the low state lies below $g^{L}\left(A^{L}\right)$.

This situation is shown in Figure 3. The dashed curves show R's profit in both states, given a binding MST of $\frac{1}{1+\lambda}$, i.e., when $\mathrm{R}$ purchases $A$ units of good A, it must purchase $\lambda A$ units of good $\mathrm{B}$. The lower dashed curve shows the function $R^{L}(A, \lambda A)$ and the higher dashed curve shows the function $R^{H}(A, \lambda A)$. Further, $R^{S}(A, \lambda A)$ is tangential to $g^{S}(A)$ where $\beta^{S}(A)=\lambda A$. 
As we can see from Figure 3, at the quantities of $A^{L}$ and $B^{L}$ that satisfy (24) and (25), M has an incentive to distort R's purchases of good B below the level it would ideally choose because although this reduces the tariff $\mathrm{M}$ can charge in the low state, it reduces R's informational rent in the high state by even more, and thus increases the tariff $\mathrm{M}$ can charge in the high state.

In terms of welfare, if the profit-maximizing quantity of good A in the MST regime is equal to the profit-maximizing quantity of good $\mathrm{A}$ in the regime with quantity targets only, then we can unambiguously say that welfare must fall. This is because - when Case 1 applies - the MST regime implies that $\mathrm{R}$ would sell fewer units of good $\mathrm{B}$ without selling more units of good A in the low-demand state. We provide an example below in which this holds with linear demand.

Case 2: Suppose $A^{L}$ and $B^{L}$ satisfy the first-order conditions (24) and (25) but are such that

$$
R^{H}\left(A^{L}, B^{L}\right)-R^{L}\left(A^{L}, B^{L}\right)+g^{L}(0)<g^{H}(0) .
$$

Then, in this situation, M maximizes overall gross surplus subject to the following constraint:

$$
R^{H}\left(A^{L}, B^{L}\right)-R^{L}\left(A^{L}, B^{L}\right) \leq g^{H}(0)-g^{L}(0) .
$$

When Case 2 applies, increasing R's gross revenue in the low-demand state allows $M$ to charge a higher $T^{L}$ without affecting the incentive-compatibility constraint. Thus $\mathrm{M}$ increases the quantity of one or both goods in the low-demand state compared to the outcome in Case 1.

An example is shown in Figure 4 below. Suppose (24) and (25) are satisfied at $A^{L}=A_{1}$ and $B^{L}=\lambda A_{1}$, but that (26) holds at these values. Then, this cannot be profit maximizing because $\mathrm{M}$ can induce $\mathrm{R}$ to sell more units of both goods in the low-demand state without affecting the tariff it charges in the high-demand state. For example, a movement of $A^{L}$ from $A_{1}$ to $A_{2}$ and a movement of $B^{L}$ from $\lambda A_{1}$ to $\lambda A_{2}$ as depicted in Figure 4 is clearly profitable since $T_{2}>T_{1}{ }^{15}$

In this instance, the constraint in (27) binds at the new, higher levels of $A^{L}$ and $B^{L}$. Of even greater interest for our purposes is the case where $\mathrm{M}$ chooses $A^{L}$ and $B^{L}$ to maximize overall gross surplus and the constraint in (27) does not bind. In this case, $A^{L}$ and $B^{L}$ solve

$$
\frac{\partial R^{L}\left(A^{L}, B^{L}\right)}{\partial A}=0
$$

and

$$
\frac{\partial R^{L}\left(A^{L}, B^{L}\right)}{\partial B}=0
$$

and the full-information outcome is obtained. We provide a linear example of this below.

\footnotetext{
${ }^{15}$ For the purpose of Figure 4, we assume that the profit-maximizing ratio of B to A is $\lambda$ and that (24) and (25) are satisfied when $B^{L}=\lambda A_{1}$. This holds in our linear example due to symmetry but need not hold in general.
} 
Figure 4: Market share targets - Case 2

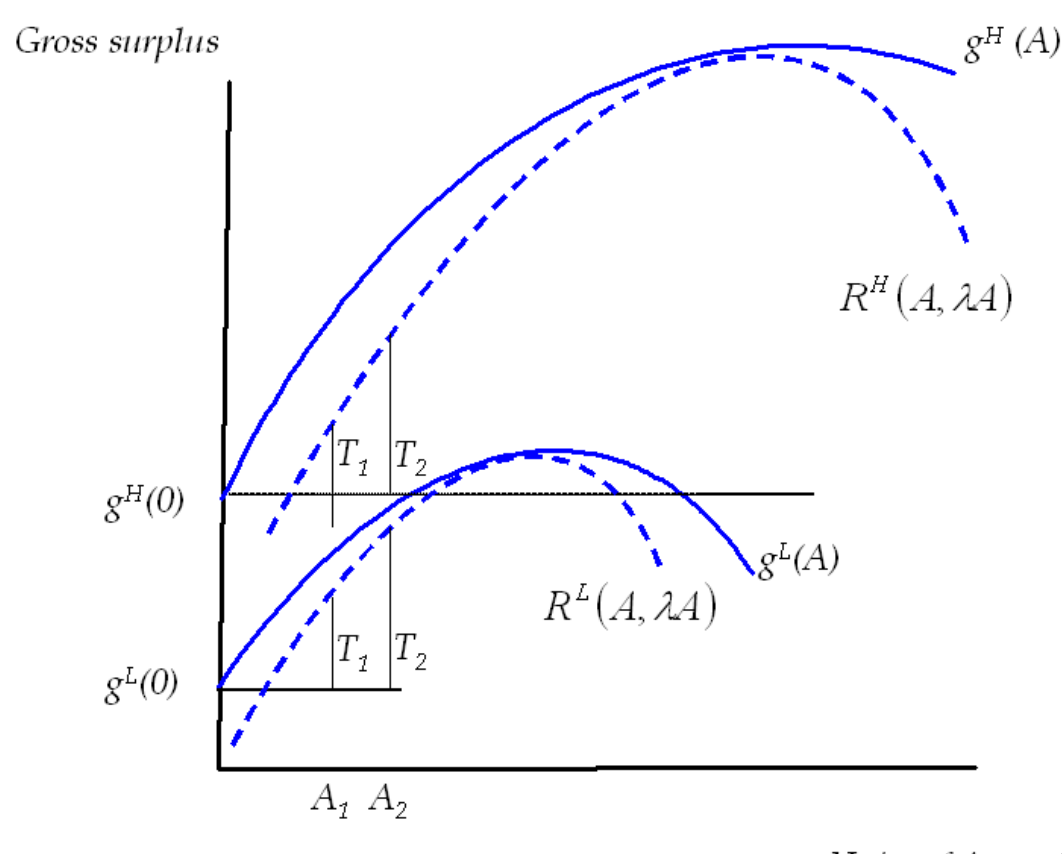

Units of A purclused

Proposition 3 When market-share contracts are feasible, $M$ induces quantities $A^{\star S}$ and $\beta^{S}\left(A^{\star S}\right)$ in state $S$ and earns payoff $R^{S}\left(A^{\star S}, \beta^{S}\left(A^{\star S}\right)\right)-g^{S}(0)$ if and only if the following condition holds:

$$
R^{H}\left(A^{\star L}, \beta^{L}\left(A^{\star L}\right)\right)-R^{L}\left(A^{\star L}, \beta^{L}\left(A^{\star L}\right)\right) \leq g^{H}(0)-g^{L}(0) .
$$

Proof: Recall that $A^{\star S}$ and $\beta^{S}\left(A^{\star S}\right)$ are the quantities of $\mathrm{A}$ and $\mathrm{B}$ respectively that maximize overall gross surplus in state $S$, for $S \in\{L, H\}$. Denote $T^{\star S}$ as the tariff that M would choose if it could observe the demand state prior to offering contracts, i.e., $T^{\star S}=R^{S}\left(A^{\star S}, \beta^{S}\left(A^{\star S}\right)\right)-g^{S}(0)$.

Suppose M offers $\mathrm{R}$ the menu of contracts $\left\{T^{\star S}, A^{\star S}, X^{\star S}\right\}$, where $X^{\star S} \equiv \frac{A^{\star S}}{A^{\star S}+\beta^{S}\left(A^{\star S}\right)}$. With these contracts, output is not distorted in any state and $\mathrm{R}$ earns its outside option in both states, provided that $\mathrm{R}$ reports the high-demand state when it occurs. But $\mathrm{R}$ must truthfully reveal the high-demand state since: $R^{H}\left(A^{\star H}, \beta^{H}\left(A^{\star H}\right)\right)-T^{\star H}=g^{H}(0) \geq R^{H}\left(A^{\star L}, \beta^{L}\left(A^{\star L}\right)\right)-T^{\star L}$.

In other words, if (30) does not hold at the full-information quantities, then incentive compatibility is violated. And if (30) does hold, then there exist contracts such that $M$ can induce truth telling, while maximizing overall surplus and minimizing R's rent. Since the full-information 
quantities are unique, no other combination of $A^{L}$ and $B^{L}$ can increase M's profit. Q.E.D.

Proposition 3 implies that MSTs can lead to the full-information outcome, where R earns no information rent in the high-demand state and there is no quantity distortion in the low-demand state. ${ }^{16}$ This is a novel finding in that it runs counter to the canonical result in the standard screening models. The intuition is that here the high-demand state may improve R's profit from dealing only in product B so much that R's profit from foregoing the contract designed for the high-demand state is pinned down by $g^{H}(0)$, even at the quantities of goods $\mathrm{A}$ and $\mathrm{B}$ that maximize $R^{L}(A, B)$. When this holds, there is no informational rent for $\mathrm{M}$ to mitigate, and consequently, $\mathrm{M}$ has no incentive to distort demand for $A$ downwards in the low-demand state.

Note that in the canonical model, the agent's reservation utility is independent of its type (which in our model would mean $g^{H}(0)=g^{L}(0)$ ), and thus the single-crossing property would ensure that (30) is never satisfied. It follows that a necessary condition for (30) to hold is that the buyer's reservation utility from trading with the dominant firm must be higher in the highdemand state than in the low-demand state (or, in other words, the buyer's outside option from trading with the competitive fringe must be worth more in the high state than in the low state).

Our result that the buyer may not earn information rent in the high-demand state when market-share contracts are feasible is foreshadowed in Jullien (2000), who shows that an agent's information rent need not be increasing in its type when there are a continuum of types and the agent's reservation utility depends on its type. However, to our knowledge, we are the first to show that such 'type dependence' can lead to the full-information outcome. Moreover, we find that this result depends on the feasible set of contracts. In our setting, the agent's (R's) information rent will be increasing in its type (demand state) if the principal (M) can choose quantity targets only, but need not be increasing in its type if market-share contracts are feasible.

Note finally that when the full-information outcome is obtained, the downward distortion that would otherwise occur on good $A$ is eliminated, but so is the upward distortion on good $\mathrm{B}$ when goods are strategic substitutes (see Bulow et al, 1985). Hence, the welfare effects of market-share contracts in this case are in general ambiguous. However, as we show in the linear example below, the positive effects on welfare from eliminating the downward distortion on good $A$ always outweigh the reduction in welfare from eliminating the upward distortion on good $B$.

\footnotetext{
${ }^{16}$ Note that the full-information outcome cannot be obtained when $\mathrm{M}$ is restricted to offering a menu of quantitytargets only because then the analogue to (30) is $R^{H}\left(A^{\star L}, \beta^{H}\left(A^{\star L}\right)\right)-R^{L}\left(A^{\star L}, \beta^{L}\left(A^{\star L}\right)\right) \leq g^{H}(0)-g^{L}(0)$, or in other words, $g^{H}\left(A^{\star L}\right)-g^{L}\left(A^{\star L}\right) \leq g^{H}(0)-g^{L}(0)$. This violates the single-crossing property (Assumption 3 ).
} 


\section{Linear Example}

Assume demand is linear and symmetric, and of the form:

$$
P_{A}^{S}=V^{S}-\frac{A}{2}-\gamma B, \quad P_{B}^{S}=V^{S}-\frac{B}{2}-\gamma A,
$$

where the price of each good is a function of the state of demand $S$, the quantity sold of goods $\mathrm{A}$ and $\mathrm{B}$, and $\gamma$, where $\gamma \in[0,1 / 2)$ is a measure of the degree of substitution between goods. To ensure that demand is higher in the high-demand state, we henceforth assume that $V^{H}>V^{L}$.

The retailer's revenue (and hence its profit given $c_{A}=c_{B}=0$ ) in state $S$ can be written as

$$
R^{S}(A, B)=P_{A}^{S} A+P_{B}^{S} B
$$

and the associated profit-maximizing (i.e., full information) quantities of $\mathrm{A}$ and $\mathrm{B}$ are

$$
A^{* S}=\frac{V^{S}}{1+2 \gamma} \quad \text { and } \quad \beta^{S}\left(A^{* S}\right)=\frac{V^{S}}{1+2 \gamma} .
$$

Solving for the quantity of good $\mathrm{B}$ that $\mathrm{R}$ would ideally like to purchase (and resell) in state $S$ as a function of how much it purchases (and resells) of good A yields:

$$
\beta^{S}(A)=V^{S}-2 \gamma A
$$

Note that $\beta^{S}(A)$ is increasing in $V^{S}$ (the size of the market) and decreasing in $A$, for all $\gamma>0$.

Substituting (34) into the retailer's revenue function yields the overall gross surplus function:

$$
g^{S}(A)=\frac{1}{2}\left(\left(V^{S}+(2-4 \gamma) A\right) V^{S}-\left(1-4 \gamma^{2}\right) A^{2}\right),
$$

from which it is straightforward to verify that Assumptions 1, 2, and 3 are satisfied, with

$$
g^{H}(0)-g^{L}(0)=\frac{\left(V^{H}\right)^{2}}{2}-\frac{\left(V^{L}\right)^{2}}{2}>0 .
$$

Thus, R's outside option if it purchases only from the competitive fringe is increasing in $S$.

\section{Quantity Targets}

In a regime with quantity targets only, M's problem is to choose $A^{L}, A^{H}$ to maximize

$$
g^{L}\left(A^{L}\right)-g^{L}(0)+(1-p)\left(g^{H}\left(A^{H}\right)-g^{H}\left(A^{L}\right)\right) .
$$

Solving the associated first-order conditions yields M's profit-maximizing choices:

$$
A^{Q T H}=A^{* H}
$$


and

$$
A^{Q T L}=\frac{V^{L}-(1-p) V^{H}}{p(1+2 \gamma)}<A^{* L} .
$$

M maximizes surplus in the high-demand state so as to extract as high a payment $T^{H}$ from $\mathrm{R}$ as possible. Meanwhile, $\mathrm{M}$ chooses $A^{L}$ to be less than $A^{* L}$ to mitigate R's information rent. Note, we assume that $p>\frac{V^{H}-V^{L}}{V^{H}}$ because otherwise $\mathrm{M}$ would not serve $\mathrm{R}$ in the low-demand state.

Note that, since $\beta^{S}(A)$ is decreasing in $A$, a distortion downward in the quantity of good $\mathrm{A}$ necessarily implies an upward distortion in the quantity purchased of good B. Thus, we have

$$
\beta^{L}\left(A^{Q T L}\right)>\beta^{L}\left(A^{* L}\right)
$$

Nevertheless, although more of good B is good for consumers, one can show that overall consumer surplus (and welfare) decreases when there is asymmetric information since the harm from the downward distortion in good A more than offsets the gain from the upward distortion in good B.

\section{Market-share Contracts}

In Case $1, \mathrm{M}$ chooses $A^{H}, B^{H}$ and $A^{L}, B^{L}$ to maximize

$$
R^{L}\left(A^{L}, B^{L}\right)-g^{L}(0)+(1-p)\left(R^{H}\left(A^{H}, B^{H}\right)-R^{H}\left(A^{L}, B^{L}\right)\right)
$$

subject to

$$
R^{H}\left(A^{L}, B^{L}\right)-R^{L}\left(A^{L}, B^{L}\right)+g^{L}(0) \geq g^{H}(0),
$$

while in Case $2, \mathrm{M}$ chooses $A^{H}, B^{H}$ and $A^{L}, B^{L}$ to maximize

$$
\left.p\left(R^{L}\left(A^{L}, B^{L}\right)-g^{L}(0)\right)+(1-p)\left(R^{H}\left(A^{H}, B^{H}\right)-g^{H}(0)\right)\right),
$$

subject to

$$
R^{H}\left(A^{L}, B^{L}\right)-R^{L}\left(A^{L}, B^{L}\right)+g^{L}(0) \leq g^{H}(0) .
$$

Let $A^{M S i}, B^{M S i}$ denote M's profit-maximizing choice of $A$ and $B$ in state $i$. Then,

$$
A^{M S H}=A^{* H}, \quad B^{M S H}=\beta^{H}\left(A^{* H}\right),
$$

and

$$
A^{M S L}=B^{M S L}= \begin{cases}A^{Q T L} & \text { if } \quad V^{H}<f\left(V^{L}, \gamma\right) \\ \left(V^{L}+V^{H}\right) / 4 & \text { if } \quad f\left(V^{L}, \gamma\right) \leq V^{H}<g\left(V^{L}, \gamma\right), \\ A^{* L} & \text { if } V^{H} \geq g\left(V^{L}, \gamma\right)\end{cases}
$$

where

$$
f\left(V^{L}, \gamma\right)=\frac{(4-(1+2 \gamma) p) V^{L}}{4-3 p+2 \gamma p}
$$


and

$$
g\left(V^{L}, \gamma\right)=\frac{(3-2 \gamma) V^{L}}{1+2 \gamma}
$$

M maximizes surplus in the high-demand state, but may or may not maximize surplus in the low-demand state depending on parameter values. For $V^{H}<f\left(V^{L}, \gamma\right), A^{M S L}=A^{Q T L}$ and $B^{M S L}<\beta^{L}\left(A^{Q T L}\right)$, implying that welfare is strictly lower when market-share contracts are feasible (vis a vis the regime with quantity-targets only), whereas for $V^{H} \geq g\left(V^{L}, \gamma\right)$, the full-information outcome is obtained with market-share contracts, and thus, one can show that welfare is strictly higher with market-share contracts. Since quantities in the regime with marketshare contracts are increasing in $V^{H}$ for $f\left(V^{L}, \gamma\right) \leq V^{H}<g\left(V^{L}, \gamma\right)$, we have the following result:

Proposition 4 There exists $\bar{V}^{H}>V^{L}$ such that for all $V^{H}>\bar{V}^{H}$, welfare is higher when market-share contracts are feasible. Conversely, welfare is lower in this case for all $V^{H}<\bar{V}^{H}$.

In summary, for relatively low values of $V^{H}$, Case 1 applies in the MST regime, and the quantity of good A that is purchased by $\mathrm{R}$ in equilibrium is the same whether or not marketshare contracts are feasible. As a result, the MST regime reduces welfare (because fewer units of good $\mathrm{B}$ are sold). Case 2 is more likely to apply when $V^{H}$ is relatively high, and when Case 2 does apply, further increases in $V^{H}$ make it more likely that the MST regime is welfare enhancing. When $V^{H}$ is sufficiently high, M obtains the full-information outcome. Thus, in this example, the MST regime reduces welfare when demand for $A$ is 'a little stronger' in the high-demand state and increases welfare when the demand for $A$ is 'a lot stronger' in the high-demand state.

\section{Bundling, fidelity rebates, all-units discounts}

In this section we consider the implications of our analysis for antitrust policy. In particular, we relate our analysis to the literatures on bundling, fidelity rebates and all-units discounts.

Bundling. The discussion in Section 3 sheds new light on why a monopolist of product A might wish to bundle its product with a competitively supplied product B. Suppose that MSTs are banned. Then the monopolist could replicate the MST outcome by employing a combination of bundling and exclusive dealing. For example, $\mathrm{M}$ could offer $\mathrm{R}$ the menu of contracts $\left\{A^{L}, B^{L}\right\}^{E}$ and $\left\{A^{* H}, B^{\star H}\right\}$, where the superscript $E$ denotes exclusivity in the low-demand state (i.e., $\mathrm{R}$ is not permitted to purchase additional quantities of good B from other sources when in this state). 
If Case 1 would have applied in the MST regime, $A^{L}$ and $B^{L}$ satisfy (24) and (25) respectively or, if Case 2 would have applied, $A^{L}$ and $B^{L}$ maximize overall gross surplus subject to (27).

According to the standard Chicago school argument, which assumes that goods are consumed in fixed proportions, a monopolist of product A would not seek to monopolize a perfectly competitive market for product B unless it were more efficient to do so. However, as shown independently by Nalebuff (2005) and Greenlee, Reitman and Sibley (2004), this argument fails to hold when the goods are not consumed in fixed proportions. ${ }^{17}$ In this paper, we add to their critique by showing in a model with asymmetric information that when MSTs are banned, M finds it profitable to monopolize the market for product B even when this might harm welfare.

Note that some form of asymmetric information is critical for bundling to be profitable in our model. If $\mathrm{M}$ could observe the state of demand prior to offering its contract, it could extract all of R's surplus (subject to R earning its reservation utility) with quantity-targets only, and there would be nothing to gained from bundling goods A and B (or from offering MSTs). But because $\mathrm{M}$ cannot observe the state of demand prior to offering its contract, it has to induce $\mathrm{R}$ to reveal its type, and so contracts with quantity targets only do not suffice to eliminate R's information rent (i.e., extract all the surplus from the sales of $A$ 's product). This inability to extract all the surplus from the sales of its product is what motivates $M$ to do better by seeking additional instruments: e.g., MST's if they are feasible, or bundling if MST's are not feasible. ${ }^{18}$

Fidelity rebates. Fidelity rebates are discounts offered either expressly or impliedly in return for a buyer placing a minimum share of its total purchase requirements with a given supplier. To qualify for the discount, it is not the absolute size of the buyer's order that matters but whether the order from the supplier is sufficiently large relative to the buyer's total purchases. ${ }^{19}$

\footnotetext{
${ }^{17}$ Nalebuff (2005) and Greenlee et al (2004) show that a monopolist of good A can bribe consumers to buy a competitively supplied good B at a premium by offering a 'must stock' good at a discount from the monopoly price if customers also source their needs of the competitive good from the monopolist. These studies show that the Chicago critique fails to hold when each customer has a downward sloping demand for the monopoly good and there is no fixed ratio of consumption for the two goods. The monopolist's strategy is profitable because it can offer a discount on its own price at little cost to itself (a second order loss in profits) while offering consumers a first order gain in utility. This means that consumers are willing to pay more for the monopolist's competitive product. It may even allow the monopolist to foreclose a more efficient producer in the competitive market.

${ }^{18}$ We implicitly assume that MST's are less costly to implement in practice than bundling. If the reverse were true, of course, then we would expect to observe bundling over MSTs whether or not MST's were feasible.

${ }^{19} \mathrm{~A}$ non-technical discussion of the competitive effects of fidelity rebates is provided in Office of Fair Trading (2005).
} 
In European competition law, fidelity rebates are viewed by competition authorities with considerable suspicion. That is to say, fidelity rebates employed by a dominant firm are arguably considered to be per se abusive. The concern is that by forcing the buyer to purchase more of a good than it otherwise would, the effect may be to 'crowd out' smaller rivals, or deny scale economies to other competitors, potentially harming consumers in both the short and long run.

In our model, market-share contracts amount to an express requirement that $\mathrm{R}$ purchase at least a threshold share of its total needs from M. These contracts are therefore an extreme form of 'share of needs' or 'fidelity' rebate, whereby failure to meet the threshold implies that a very substantial discount is forgone (i.e. the price of good A rises to infinity if the threshold is missed). Thus our model provides a setting where fidelity rebates combined with quantity targets are more profitable than quantity targets alone, with ambiguous effects for welfare. Crowding out of the fringe firms does indeed occur in equilibrium, but consumers may gain if the quantity sold by the dominant firm when it employs the market-share contracts increases sufficiently.

One can also think of fidelity rebates as arising impliedly in the regime with quantity targets only. Suppose that instead of there being two demand states, there are two buyers, one large and one small, but where $\mathrm{M}$ is prohibited from directly discriminating between buyers. When $\mathrm{M}$ seeks to discriminate indirectly by inducing each buyer to reveal its true type, it may be that the profit-maximizing contracts give rise to discount structures in which one buyer obtains a lower per unit price than the other buyer and in which it purchases a higher share of its total needs from M. ${ }^{20}$ Such a contract may well be viewed as containing an implied fidelity rebate by the authorities. In these cases, however, there is nothing pernicious about the contracts per se. Whether or not the profit-maximizing contracts have this form, M's motive remains the same. Fidelity rebates if arising in this scenario are not used with exclusionary intentions but simply as a device to induce buyers to reveal their true types, again with ambiguous effects for welfare.

All-units discounts. Our discussion of the regime with quantity targets allows us to extend the insights of Kolay et al (2004) regarding the use of all-units discounts or 'rollback rebates'. All-units discounts arise when, on reaching a given quantity target, the buyer qualifies for a discount not only on the additional units purchased but also on all the units purchased up to the target. As with fidelity rebates, such discounts are often viewed with suspicion in competition

\footnotetext{
${ }^{20}$ Such a discount structure is less likely to be viewed with suspicion if it is the larger buyer that receives the lower per unit price. In European law, discounts for larger buyers are easier to justify for efficiency reasons.
} 
law - especially when the target is set close to the total requirements of the buyer in question. ${ }^{21}$

Our model implies that market-share contracts are more profitable than all-units discounts, which in turn are more profitable than menus of two-part tariffs. The first claim follows because, as we have shown, market-share contracts are more profitable than contracts with quantity targets only, and a quantity-targets only regime can always replicate the most profitable outcome in an all-units discount regime. Where the all-units discount regime can replicate the profitmaximizing quantity target regime outcome, the two regimes are equivalent in terms of profitability, otherwise the all-units discount regime is strictly less profitable. ${ }^{22}$ Our second claim, that all-units discounts are more profitable than a menu of two-part tariffs, follows from Kolay et al (2004), whose analysis carries over to the model discussed in Section 2 of this paper, where $\mathrm{R}$ may also buy a competitively-supplied substitute product. The implication is that where a supplier wants to induce a retailer to reveal the true demand state, firms will prefer market-share contracts to discount schemes that are not conditional on purchases of rival products (unless market-share contracts are banned or infeasible, e.g. because verification of a buyer's total needs is not possible). ${ }^{23}$ Permitting market-share contracts in this case is not necessarily harmful.

Finally, note that competition authorities tend to consider two-part tariffs to be less harmful than fidelity rebates. ${ }^{24}$ However, in terms of welfare, two-part tariffs do not necessarily perform better. ${ }^{25}$ Consider our example with linear demand. It can be shown that two-part tariffs and market-share contracts give rise to the same quantity of good A in the low-demand state (and identical quantities of goods A and B in the high-demand state) when Case 1 applies. In this case, market-share targets perform poorly for welfare in relation to two-part tariffs because the quantity of good B is lower in the low-demand state, while all other quantities are the same.

\footnotetext{
${ }^{21}$ See, for example, the DG Competition (2005), section 7 and Whish (2003; 695).

${ }^{22}$ Note that all-units discounts replicate the quantity-target regime when the slope of the gross surplus function in the high-demand state evaluated at $A^{Q T L}$ is weakly less than $A^{Q T L} / T^{L}$. This result is potentially helpful in that it is easier analytically to 'work' with the quantity-targets regime than with the all-units discount regime.

${ }^{23}$ We have concentrated on the simplest scenario. However, it is straightforward to extend the model to an arguably more 'realistic' case where retailers engage in promotional expenditure. For example, suppose retailers are of type $\mathrm{H}$ or type $\mathrm{L}$ (these types being unknown to $\mathrm{M}$ when setting contracts), with each retailer engaging in a fixed promotional expenditure which generates demand for both products A and B. Then, our analysis extends as long as the gross surplus function (now net of the fixed promotional expenditure) satisfies our assumptions.

${ }^{24}$ See, for example, the DG Competition (2005), section 7. In particular paragraph 168 states that 'incremental' rebates (i.e., a menu of two-part tariffs) would be found abusive only if the discounted price was predatory.

${ }^{25}$ Kolay et al (2004) found the welfare effects of all-unit discounts relative to two-part tariffs to be ambiguous.
} 
However, if Case 2 applies, market-share targets can be better for welfare. ${ }^{26}$ Thus, a priori there is no reason to presume that fidelity rebates are necessarily more harmful than two-part tariffs (or other discount schemes that do not condition rewards on purchases made with rival suppliers). Of course, neither is there support for the view that they should be presumed beneficial.

\section{Concluding remarks}

In this paper we considered a setting of asymmetric information in which $\mathrm{M}$, a monopolist of good $\mathrm{A}$, offers a menu of contracts to induce $\mathrm{R}$, a retailer of goods $\mathrm{A}$ and $\mathrm{B}$, to reveal the true state of demand. We found that when $\mathrm{M}$ was restricted to contracting only over its own quantity, allowing $\mathrm{R}$ to purchase good $\mathrm{B}$ did not alter standard results in screening models (i.e., output is distorted downwards in the low state, and $\mathrm{R}$ earns an information rent in the high state).

We then considered the impact of market-share contracts, which allow $M$ to contract indirectly on how much $\mathrm{R}$ purchases of both goods A and B. We gave conditions under which market-share contracts were profitable and showed that they had ambiguous consequences for welfare. Further, we presented the novel result that under some conditions, market-share contracts could allow $\mathrm{M}$ to overcome its asymmetric information and obtain the full information outcome (i.e., where M knows demand in advance of setting contracts and so neither distorts output in the low-demand state nor allows $\mathrm{R}$ an information rent in the high-demand state).

Our welfare results were derived in the context of a linear example. We compared welfare under a market-share contract regime to welfare under a regime in which only quantity targets were feasible. We found that allowing market share contracts was harmful when demand was only 'a little stronger' in the high-demand state. In contrast, we found that allowing marketshare contracts was welfare enhancing when demand was 'a lot stronger.' Further, we found that when demand was sufficiently strong in the high state, market-share contracts could lead to the full-information outcome. We found identical welfare results when we compared the regime with market-share contracts to a regime in which only menus of two-part tariffs were feasible.

Finally, we discussed how market-share contracts could be replicated by a combination of bundling and exclusive dealing. We provided a new reason for a monopolist to bundle its product with a competitively-supplied product, and we argued that even though the rival product was supplied competitively, a presumption that such bundling would be welfare enhancing would

\footnotetext{
${ }^{26}$ Case 2 leads to more units of good A but fewer units of good B in the low-demand state relative to the two-part tariff and quantity-target regimes. This leads to higher consumer surplus and welfare in our example.
} 
not be appropriate. We also compared market-share contracts to fidelity rebates, defined here to be discounts based on the share of a buyer's needs sourced from a supplier, and showed that such rebates can lead to efficient outcomes when a dominant supplier cannot identify the total needs of its buyers and thus are not necessarily employed with a view to harming competition.

A final thought on the welfare effects of market-share contracts is appropriate. Competition authorities are for the most part concerned that the adoption of such contracts by a dominant firm will lead to a crowding out of competitors or the denial of scale economies to smaller rivals. Here, crowding out is indeed observed in equilibrium (although rivals are not denied scale economies). In the absence of market-share contracts, $\mathrm{R}$ compensates for the fact that its purchases of good A are distorted downward by buying more of good B than it otherwise would. By employing a market-share contract, M can prevent this, causing the output of good $\mathrm{B}$ to fall relative to what it would have been. By itself, this effect is harmful to consumers and social welfare. However, the flip side of this is that market-share contracts can mitigate M's asymmetric information, reducing the incentives for $\mathrm{M}$ to distort downward its own quantity in the low-demand state. Thus, there is often a tradeoff for consumers and for welfare. Although some quantity of good B is crowded out, the quantity of good A often increases. If it increases by enough, overall welfare may actually be higher, which we confirmed in our linear example. 


\section{References}

Bulow, J., Geanakoplos, J. and P. Klemperer (1985), Multimarket Oligopoly: Strategic Substitutes and Complements, Journal of Political Economy, 93: 488-511.

Caillaud and Hermalin (2000), Hidden-Information Agency, working paper, University of California at Berkeley.

Dewatripont, M. and P. Bolton (2005), Contract Theory, MIT Press: Cambridge, MA.

DG Competition (2005), discussion paper on the application of Article 82 of the Treaty to exclusionary abuses, December.

Greenlee, P. and D. Reitman (2004), Competing with Loyalty Discounts, working paper, U.S. Department of Justice.

Greenlee, P., Reitman, D., and D. Sibley (2004), An Antitrust Analysis of Bundled Loyalty Discounts, working paper, U.S. Department of Justice.

Heimler, A. (2005), Below-Cost Pricing and Loyalty-Inducing Discounts: Are They Restrictive and, If So, When?" Competition Policy International, 1: 149-172.

Jullien, B. (2000), Participation Constraints in Adverse Selection Models, Journal of Economic Theory, 93: 1-47.

Kobayashi, B. (2005), The Economics of Loyalty Discounts and Antitrust Law in the United States, Competition Policy International, 1: 115-148.

Kolay, S., Shaffer, G., and J. Ordover (2004), All-Units Discounts in Retail Contracts, Journal of Economics \&3 Management Strategy, 13: 429-459.

Lewis, T. and D. Sappington (1989), Countervailing Incentives in Agency Problems, Journal of Economic Theory, 49: 294-313.

Marvel, H. and H. Yang (2006), Group Purchasing, Nonlinear Tariffs, and Oligopoly, working paper, Ohio State University.

Marx, L. and G. Shaffer (2004), Rent-Shifting, Exclusion, and Market-Share Discounts, working paper, University of Rochester.

Mills, D. (2004), Market-Share Discounts, working paper, University of Virginia. 
Nalebuff B. (2003), Bundling, Tying and Portfolio Effects Part I: Conceptual Issues, DTI Economics Paper No. 1.

Nalebuff, B. (2005), Exclusionary Bundling, Antitrust Bulletin, 50: 321-370.

Ordover, J. and G. Shaffer (2006), Exclusionary Discounts, working paper, University of Rochester.

Office of Fair Trading (2005), Selective Price Cuts and Fidelity Rebates, Economic Discussion Paper, A report prepared for the Office of Fair Trading by RBB Economics.

Salanie, B. (1997), The Economics of Contracts, MIT Press: Cambridge MA.

Spector, D. (2005), Loyalty Rebates: An Assessment of Competitive Concerns and a Proposed Structured Rule of Reason, Competition Policy International, 1: 89-114.

Symposium on Loyalty Rebates (2005), Competition Policy International, 1: 89-173.

Whish, R. (2003), Competition Law, 5th Edition, Reed Elsevier (UK) Ltd. 